\title{
The future of plastic surgery
}

\author{
Peter C. Neligan
}

Professor Emeritus, University of Washington, Seattle, WA, USA

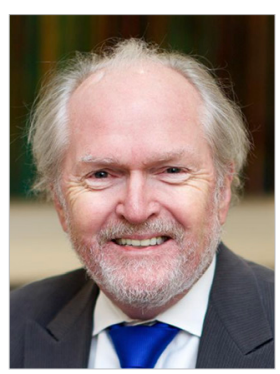

I am often asked, especially by trainees, if I think there is a future in plastic surgery. As a specialty, we have been under siege for a long time. Aesthetic surgery is plagued by "wannabees", surgeons from other specialties, and even non-surgeons, who want a piece of the pie. I have even been told by patients that facial plastic surgeons (the majority of whom are otolaryngologists) have said to them "Why go to a general plastic surgeon when I am purely a facial plastic surgeon." However this turf war is not confined to aesthetic surgery. When I trained in the 1970's plastic surgeons did head and neck resections as well as reconstructions. Currently, in the United States, plastic surgeons, except in a few centers, do not even do the reconstructions. Head and neck surgeons do both. General surgeons were often head and neck surgeons. Nowadays they rarely are. In many parts of the world, cleft lip and palate surgery is done by oral surgeons, not plastic surgeons. Similarly, gynecologists do breast surgery in some parts of the world. I was trained in the surgical management of hypospadias, something that is now exclusively in the domain of the urological surgeon.

Why is this happening? Part of the reason is availability. For example, a breast surgeon who has done a mastectomy waits for the plastic surgeon, who may be busy in another operating room, to come and put the expander in. She or he thinks, "why don't I put it in myself? It can't be that hard." It is not. That's the thin end of the wedge that may ultimately lead to the plastic surgeon no longer being asked to do the reconstruction. Where are we vulnerable? High-volume conditions are attractive because there is room for others and they are potentially lucrative. Also, plastic surgeons are not gatekeepers. People with a head and neck problem see a head and neck surgeon. Patients with a breast problem see a breast surgeon. We therefore rely on these specialties to refer patients to us for reconstruction. I was recently invited to give a talk on lymphedema at the American Vein and Lymphatic Society. This body used to be known as the American College of Phlebology. I asked the president why they changed the name of the society. His answer was "We want to own the Lymphatic System."

This is not new. Traditionally plastic surgeons have developed an innovation in a particular field $[1,2]$. Another specialty starts to copy what we have done and eventually takes it over. We then go and innovate something else! There are multiple examples of this in our history.

So, what can we do about this?

-We need to be the best at what we do

-We need to be available (sometimes an inconvenience)

- We need to be affable (nobody wants to work with a grouch)

-We need to collaborate (this often means some give and take)

-We need to continue to innovate and develop solutions for conditions that have no solution (lymphatic surgery is an example)

What we really need is to become part of the team. This means not just being available in the operating room. We must also become involved in multidisciplinary conferences and tumor boards. Involvement means participation, not just showing up. Just being a technician who comes in at the end of a case is not enough.

So, to answer the question as to whether I am worried about 
the future of plastic surgery the answer is an emphatic "No." Plastic surgery is an amazing specialty that continues to have a bright future.

\section{NOTES}

\section{Conflict of interest}

No potential conflict of interest relevant to this article was reported.

\section{ORCID}

Peter C. Neligan

\section{REFERENCES}

1. Hallock GG. Innovations: a dawning of a new age. Arch Plast Surg 2021;48:147-8.

2. Hong JP. Innovation in plastic surgery-why and how? Arch Plast Surg 2021;48:471-2.

Correspondence: Peter C. Neligan

University of Washington, 1515 West Winter Drive, Phoenix, AZ 85021, USA E-mail:pneligan@uw.edu

Received: December 31, $2021 \bullet$ Revised: January 6, 2022 • Accepted: January 7, 2022 pISSN: 2234-6163 • eISSN: 2234-6171

https://doi.org/10.5999/aps.2021.02278 • Arch Plast Surg 2022;49:1-2 